\title{
PRODUÇÃO DE CAROTENOIDE-SARCINAXANTINA A PARTIR MICROCOCCUS LUTEUS ISOLADO DO SEMIÁRIDO BRASILEIRO E SUAS ATIVIDADES BIOLÓGICAS
}

\author{
Karine C. Schmidt ${ }^{1}$, Tayane C. D. Mendes-Silva ${ }^{2}$, Louise M. S. Oliveira ${ }^{3}$, Esteban E. Vidal ${ }^{4}$, \\ Rosileide F. S. Andrade5, Lívia C. A. de Araújo², Marcio A. Ootani5 ${ }^{5}$, Maria B. M. Oliveira², Maria T. \\ S. Correia ${ }^{2}$, Brígida T. L. Lucena ${ }^{6}$ and Márcia V. Silva ${ }^{2,7^{*}}$
}

${ }_{1}^{1}$ Departamento de antibióticos, Centro de Biociências, Universidade Federal de Pernambuco, Recife, Pernambuco, 50670901, Brasil; ${ }^{2}$ Departamento de bioquímica, Centro de Biociências, Universidade Federal de Pernambuco, Recife, Pernambuco, 50670-901, Brasil; ${ }^{3}$ Departamento de Engenharia Agrícola e Solos, Centro de ciências Agrárias, Universidade Federal do Piauí; ' ${ }^{2}$ aboratório de Bioprocessos, Centro de Tecnologias Estratégicas do Nordeste, Recife, Pernambuco, 50740-545, Brasil; ${ }^{5}$ Núcleo de Pesquisas em Ciências Ambientais e Biotecnologia, Universidade Católica de Pernambuco, Recife, Pernambuco, Brasil; ${ }^{6}$ Centro de Ciências Biológicas e Sociais Aplicada, Universidade Estadual da Paraíba, Campus V, Campina Grande, Paraíba, 58429-500, Brasil; ${ }^{7}$ Núcleo de Bioprospecção e Conservação da Caatinga, Instituto Nacional do Semiárido/Ministério da Ciência, Tecnologia, Inovação e Comunicações, Brasil

\section{ARTICLE INFO}

Article History:

Received $17^{\text {th }}$ March, 2021

Received in revised form

$02^{\text {nd }}$ April, 2021

Accepted $26^{\text {th }}$ May, 2021

Published online $30^{\text {th }}$ June, 2021

Key Words:

Bactérias; carotenoides;

Antioxidante e atividade fotoprotetora.

*Corresponding author:

Karine C. Schmidt

\begin{abstract}
Este estudo relata a investigação de carotenoides produzidos por dois isolados bacterianos (FT9.12 e FT-5.10) de solo do Domínio Caatinga e avalia suas atividades biológicas. Os isolados bacterianos pigmentados foram identificados por análises bioquímicas e moleculares (sequenciamento do gene $16 S$ rRNA) como Micrococcus luteus. Os carotenoides foram caracterizados através de Cromatografia Líquida de Alta Eficiência, e mostraram perfis cromatográficos semelhantes para ambos os isolados FT-9.12 e FT-5.10, apresentando como compostos majoritários o carotenoide sarcinaxantina e seus derivados (Tempo de retenção 3,88 min e 4,03 $\mathrm{min}$ ), respectivamente. As atividades antioxidantes foram determinadas por métodos in vitro, destacando-se o método de inibição da oxidação do $\beta$-caroteno que exibiu uma taxa de $78,65( \pm 7,046) \%$ para M. luteus FT-9.12. O valor de Fator de Proteção Solar (FPS) foi de 4,26( $\pm 0,83)$ para o isolado M. luteus FT-5.10. A partir dos resultados obtidos, M. luteus demonstrou capacidade de produzir um carotenoide raro, sarcinaxantina, com potencial para composição de formulações antioxidantes e fotoprotetoras.
\end{abstract}

Copyright (C) 2021, Karine C. Schmidt et al. This is an open access article distributed under the Creative Commons Attribution License, which permits unrestricted use, distribution, and reproduction in any medium, provided the original work is properly cited.

Citation: Karine C. Schmidt, Tayane C. D. Mendes-Silva, Louise M. S. Oliveira, Esteban E. Vidal, Rosileide F. S. Andrade et al., 2021. "Produção de carotenoide-sarcinaxantina a partir micrococcus luteus isolado do semiárido brasileiro e suas atividades Biológicas", International Journal of Development Research, 11, (06), 47983-47986.

\section{INTRODUCTION}

Os carotenoides são pigmentos naturais lipofílicos originados da via biossintética dos terpenoides, cuja coloração varia do amarelo ao vermelho (BONET et al., 2015; MENDES-SILVA et al., 2020). Estruturalmente, a maioria dos carotenoides possuem 40 carbonos em sua estrutura, um pequeno número possui 30 carbonos e um número ainda menor possui 50 carbonos (NETZER et al., 2010). Esses últimos (C50) são sintetizados por bactérias da ordem Actinomycetales e por bactérias Gram-negativas Pseudomonas (MIKI et al. 1994; MATA-GÓMEZ et al, 2014). Esses pigmentos carotenoides são encontrados em plantas, micro-organismos e apresentam atividade biológica atuando na proteção contra danos foto-oxidativos em organismos não fotossintéticos, possuem capacidade de eliminação de $\mathrm{O}_{2}$ e outros tipos de espécies reativas de oxigênio, além de possuir potencial no combate a alguns tipos de câncer doenças vasculares, catarata e Alzeimer (HEIDER, 2012; MANIMALA; MURUGESAN, 2014; MATA-GOMEZ, 2014; SHINDO; MISAWA, 2014; KIOKIAS; PROESTOS; VARZAKAS, 2016). Devido às referidas propriedades dos pigmentos, essas moléculas vêm destacando-se em aplicações nas indústrias química, cosméticos, farmacêutica e nas indústrias de alimentos, por funcionarem também como corantes naturais e suplemento alimentar (MENDES-SILVA et al., 2021). Estudos demonstram que as bactérias têm se mostrado fonte promissora para produção de pigmentos carotenoides por serem cultivadas em curto espaço de tempo e principalmente por ser cultivada em substratos renováveis contribuindo com a produção "eco-friendly" e reduzindo o custo do processo para produção comercial em larga escala. Dentre as bactérias, M. luteus é uma actinobactéria que já foi descrita como 
potencial produtora de um carotenoide raro (C50) (NETZER et al., 2010). O Domínio Caatinga é um ambiente hostil para o desenvolvimento da maioria dos organismos, especialmente para o crescimento de micro-organismos que habitam o solo. Porém, aquelas espécies microbianas que conseguem superar as temperaturas elevadas, baixa umidade e alta taxa de incidência de radiação solar, são geralmente altamente adaptadas e em especial, produtoras de interessantes moléculas naturais com diversas aplicações biológicas (MENDES-SILVA, ANDRADE, OOTANI et al., 2020). Dessa forma, faz-se necessário o desenvolvimento de pesquisas de bioprospecção nessa área com rica biodiversidade (DUARTE et al., 2012; APGAUA et al., 2014; MENEZES et al., 2015). Portanto, o objetivo deste trabalho foi investigar pela primeira vez a produção de pigmentos carotenoides por cepas de M. luteus obtidos do solo da Caatinga do Nordeste brasileiro e avaliar sua ação antioxidante e fotoprotetora.

\section{MATERIAIS E MÉTODOS}

As bactérias foram isoladas de amostras de solos coletadas na Reserva Particular do Patrimônio Natural (RPPN) Fazenda Tamanduá (Santa Terezinha - PB na Mesorregião do Sertão paraibano) pelo grupo de Diversidade e Biotecnologia de micro-organismos da Universidade Estadual da Paraíba. As amostras foram coletadas assepticamente em sacos plásticos na camada $0-20 \mathrm{~cm}$ do solo, transportadas para o laboratório a $4{ }^{\circ} \mathrm{C}$, e foram mantidas na geladeira até o processamento. Após enriquecimento $(5 \mathrm{~g}$ de solo foi incubado em $50 \mathrm{ml}$ de TSB a $5 \%$, acrescido de $1 \%$ de glicose, por 7 dias sob agitação) $100 \mu \mathrm{L}$ da diluições $10^{-6}$ foram semeados no meio TSB (acrescido de 1,5\% de ágar) suplementado com cicloheximidina (50 $\mathrm{mg} / \mathrm{mL}$ ). As colônias selecionadas foram purificadas por esgotamento no meio TSB (acrescido de 1,5\% de agar) (SOARES JR et al., 2012). Testes bioquímicos básicos foram realizados nos dois isolados bacterianos FT-9.12 e FT-5.10, como a coloração de Gram (PELCZAR; CHAN; KRIEG, 2012), prova da catalase, teste do crescimento em ágar manitol salgado e teste de bacitracina de acordo com a metodologia de Brasil, 2013, e prova da hidrólise da bile esculina (BRASIL, 2004). O DNA genômico foi extraído de células de bactérias cultivadas em meio de cultura Luria Bertani (LB) a $37^{\circ} \mathrm{C}$ por 48 horas, segundo metodologia descrita por Sambrook et al. (2001) e o gene 16S $r R N A$ foi amplificado por PCR utilizando os seguintes oligonucleotídeos iniciadores: fD1 (5'AGAGTTTGATCCTGGCTCAG-3') e rD1 (5'AAGGAGGTG ATCCAGCC-3') (WEISBURG et al.,1991). Os produtos amplificados foram sequenciados em sequenciador automático de DNA ABI 3500. As sequências resultantes foram analisadas usando as ferramentas Pregap4 e Gap4 do pacote de softwares STADEN 1.6 e submetidas à busca de similaridade no banco de dados do Centro Nacional de Informação Biotecnológica (NCBI), utilizando a ferramenta Blast N (ALTSCHUL et al., 1997), e Ribosomal Database Project (RDP). A identificação bacteriana foi assumida quando a sequência de consulta mostrou similaridade $>97 \%$ para o gene $16 \mathrm{~S}$ $r R N A$ (GEVERS et al., 2005).

Os isolados bacterianos de coloração amarela foram cultivados em meio TSB a $30{ }^{\circ} \mathrm{C}$, a $180 \mathrm{rpm}$ por $48 \mathrm{~h}$. Posteriormente, as células foram coletadas por centrifugação a $14.000 \mathrm{rpm}$ durante 6 minutos, em que o pellet obtido foi lavado com água esterilizada. A extração dos carotenoides foi realizada a partir da biomassa seca, de acordo com as metodologias descritas por Netzer et al. (2010) e Kaiser et al. (2007). Em seguida, os extratos obtidos foram secos em rotaevaporador a $40{ }^{\circ} \mathrm{C}$ e foram submetidos a um processo de saponificação (MELÉNDEZ-MARTÍNEZ; VICARIO; HEREDIA, 2007). Os extratos foram secos novamente em rotaevaporador e os materiais residuais foram ressuspendidos em $10 \mathrm{~mL}$ de álcool metílico. Ao final, foi feita a filtração dos pigmentos extraídos através de membrana hidrofóbica PTFE com 0,45 micrômetros. Os extratos obtidos foram analisados através de cromatografia líquida de alta eficiência (HPLC) para caracterização dos carotenoides, utilizando a coluna SunFire C18 (4,6 x $150 \mathrm{~mm})$, com uma fase móvel de acetonitrila/metanol/acetato de etila (10:50:40) e o comprimento de onda de $450 \mathrm{~nm}$. O betacaroteno foi utilizado como padrão externo. A avaliação da capacidade em sequestrar o radical livre DPPH• foi realizada de acordo com a metodologia descrita por Blois (1958). Numa microplaca de 96 poços, $40 \mu \mathrm{L}$ dos extratos metanólicos nas concentrações $1000,500,250,125,62,5,31,25,16,25$ e $7,56 \mu \mathrm{g} / \mathrm{mL}$, reagiram com $250 \mu \mathrm{L}$ de solução metanólica de $\mathrm{DPPH} \bullet$ durante 25 minutos, ao abrigo da luz. A medida da absorbância foi realizada no comprimento de onda de $517 \mathrm{~nm}$ em um leitor de Microplacas. Todas as análises foram feitas em triplicata. $\mathrm{O}$ ácido gálico foi utilizado como padrão. A percentagem de sequestro de radical livre (\%SRL) foi calculada pela seguinte Equação 1:

(Abs.controle - Abs. amostra)

$\operatorname{SRL}(\%)=\frac{(\text { Abs. controle }}{\text { A }} 100$

Este método foi realizado segundo Re e colaboradores (1999). O radical ABTS+ foi preparado a partir da reação de $7,81 \mathrm{~mL}$ da solução de ABTS com $0,137 \mathrm{~mL}$ da solução de persulfato de potássio. A mistura permaneceu no escuro, à temperatura ambiente, por 16 horas. Em seguida, $1 \mathrm{~mL}$ desta mistura foi diluída em álcool etílico até obter uma absorbância de $0,700( \pm 0,020) \mathrm{nm}$ a $734 \mathrm{~nm}$. Foi preparada uma curva padrão com o Trolox com concentrações que variam de 100 a $2000 \mu \mathrm{M}$. Foram adicionadas $10 \mu \mathrm{L}$ das amostras dos extratos metanólicos brutos na concentração $1000 \mu \mathrm{g} / \mathrm{mL} \mathrm{em} 1 \mathrm{~mL}$ do reagente de ABTS e a absorbância das amostras foi determinada exatamente após 6 minutos no comprimento de onda de $734 \mathrm{~nm}$. O BHT foi utilizado como padrão. Os resultados foram expressos em Capacidade Antioxidante Equivalente ao Trolox (TEAC). O FRAP foi realizado de acordo com Benzie e Strain (1996). O reagente foi preparado misturando-se tampão acetato de sódio $300 \mathrm{mM}$ a pH 3,6, solução de TPTZ $10 \mathrm{mM}$ em HCl $40 \mathrm{mM}$ e solução de cloreto férrico $20 \mathrm{mM}$ na proporção 10:1:1. O BHT foi utilizado como padrão. Numa microplaca de 96 poços foram adicionados $180 \mu \mathrm{L}$ do reagente e $20 \mu \mathrm{L}$ do padrão ou extrato e incubados durante trinta minutos a 37 ${ }^{\circ} \mathrm{C}$. A leitura da absorbância foi realizada a $593 \mathrm{~nm}$. Foi preparada uma curva padrão com o sulfato ferroso heptahidratado com concentrações que variam de 500 a $2000 \mu \mathrm{M}$. Os resultados foram expressos em $\mu \mathrm{M}$ de sulfato ferroso $/ \mathrm{g}$ extrato (atividade antioxidante equivalente ao sulfato ferroso heptahidratado). A medida da atividade antioxidante pela oxidação acoplada do beta-caroteno e do ácido linoleico foi realizada de acordo com o método descrito por Kabouche e colaboradores (2007). Foram pesados 0,5 mg de betacaroteno e diluídos em $1 \mathrm{~mL}$ de clorofórmio. Em seguida, foram adicionados $25 \mu \mathrm{L}$ de ácido linoleico e $200 \mathrm{mg}$ de monopalmitato de polioxietileno sorbitan. $\mathrm{O}$ clorofórmio foi evaporado a $40{ }^{\circ} \mathrm{C}$. Em seguida $100 \mathrm{~mL}$ de água destilada foi adicionada aos poucos agitando vigorosamente para formar uma emulsão. As amostras foram diluídas nas seguintes concentrações: $25,50,100,200$ e $400 \mu \mathrm{g} / \mathrm{mL} .50 \mu \mathrm{L}$ da amostra foi adicionada à $1 \mathrm{~mL}$ da emulsão e $200 \mu \mathrm{L}$ desta mistura foram colocados numa microplaca. $\mathrm{O}$ tempo zero $\left(\mathrm{A}_{0}\right)$ foi medido imediatamente à $470 \mathrm{~nm}$ e as amostras foram incubadas por $2 \mathrm{~h}$ a 50 ${ }^{\circ} \mathrm{C}$. A absorbância foi determinada novamente após 120 minutos $\left(\mathrm{A}_{120}\right)$. O mesmo procedimento foi realizado com o BHT para ser utilizado como padrão. O cálculo da inibição foi realizado com a seguinte Equação 2:

Inibição $(\%)=\frac{(\text { Abs.controle }- \text { Abs. amostra })}{\text { Abs. controle }} \times 100$

Soluções metanólicas de concentração $100 \mathrm{mg} L$ foram preparadas em triplicata com o extrato bruto dos isolados e a absorbância determinada em espectrofotômetro nos seguintes comprimentos de onda: $290,295,300,305,310,315$ e $320 \mathrm{~nm}$. Os valores obtidos foram utilizados para o cálculo do FPS utilizando a seguinte Equação 3: 320

$\mathrm{FPS}=\mathrm{FC} \cdot \Sigma \mathrm{EE}(\lambda) \cdot \mathrm{I}(\lambda) \cdot \operatorname{Abs}(\lambda)$ 290 
Onde: $\mathrm{FC}=$ fator de correção; $\mathrm{EE}(\lambda)=$ efeito eritematógeno da radiação solar em cada comprimento de onda $(\lambda)$; $(\lambda)=$ intensidade da luz solar no comprimento de onda $(\lambda)$; Abs $(\lambda)=$ leitura espectrofotométrica da absorbância da formulação em solução no comprimento de onda $(\lambda)$. Todos os experimentos foram realizados em triplicata. Os dados dos experimentos foram representados por média $( \pm \mathrm{SD})$ e analisados com o programa GraphPad Prism 5. Diferenças foram consideradas significativas quando $\mathrm{P}<0.05$.

\section{RESULTADOS E DISCUSSÃO}

As sequências do $16 \mathrm{~S} r R N A$ dos dois isolados bacterianos (FT-9.12 e FT-5.10) utilizados neste estudo para avaliação da produção de corantes naturais apresentaram $99,7 \%$ de similaridade com as sequências conhecidas de $M$. luteus. Os testes bioquímicos corroboram com a identificação molecular confirmando a identidade dos isolados bacterianos como M. luteus (Tabela 1). É uma bactéria aeróbica, não formadora de esporos, que é encontrada principalmente em solo, e é capaz de sobreviver sob condições estressantes, como extremos de temperatura e baixa quantidade de nutrientes (UMADEVI; KRISHNAVENI, 2013) (MOHANA, THIPPESWAMY, ABHISHEK, 2013; VENTURA et al., 2007; SILVA et al., 2015).

Tabela 1. Identificação bioquímica dos isolados de Micrococcus luteus

\begin{tabular}{lll}
\hline Provas Bioquímicas & FT-5.10 & FT-9.12 \\
\hline $\begin{array}{l}\text { Coloração de Gram } \\
\text { Morfologia }\end{array}$ & $\begin{array}{l}\text { Positivo } \\
\text { Cocos com arranjos } \\
\text { em cachos }\end{array}$ & $\begin{array}{l}\text { Positivo } \\
\text { Cocos com } \\
\text { arranjos em cachos }\end{array}$ \\
$\begin{array}{l}\text { Catalase } \\
\text { Sensibilidade à bacitracina }\end{array}$ & $\begin{array}{l}\text { Positivo } \\
\text { Prescitivo }\end{array}$ \\
$\begin{array}{l}\text { Manitol salgado } \\
\text { Motilidade }\end{array}$ & Positivo \\
Coloração & Negativo & Negativo \\
\hline
\end{tabular}

As análises realizadas por HPLC dos isolados M. luteus FT-9.12 e FT-5.10 mostraram perfis semelhantes para ambos os isolados, destacando a presença de um composto majoritário nos tempos de retenção de 3,8 e 4,0 min, respectivamente (Tabela 2). Os dados das análises de varredura $(200-600 \mathrm{~nm})$ exibiram três valores máximos de adsorção, 415,5 nm e 439,7 nm 468,9 nm (Tabela 2), típicos do carotenoide sarcinaxantina e seus derivados segundo Netzer et al. (2010). De acordo com os resultados obtidos, M. luteus FT-9.12 produziu $12,01 \mathrm{mgL}$ de sarcinaxantina, enquanto $M$. luteus $\mathrm{FT}-5.10$ produziu $0,75 \mathrm{mg} L$ de sarcinaxantina.

Tabela 2. Análise por HPLC dos extratos brutos dos isoladosde Micrococcus luteus

\begin{tabular}{llll}
\hline M. luteus & $\begin{array}{l}\text { TR } \\
\text { (minutos) }\end{array}$ & $\begin{array}{l}\text { Comprimento de onda } \\
\lambda \text { máximo }(\mathrm{nm})\end{array}$ & $\begin{array}{l}\text { Concentração } \\
(\mathrm{mg} / \mathrm{mL})\end{array}$ \\
\hline FT-5.10 & 4,022 & $415,5,439,7,468,9$ & 0,74 \\
\hline FT-9.12 & 3,9 & $415,5,439,7,468,9$ & 12,079 \\
\hline
\end{tabular}

O carotenoide sarcinaxantina é pouco encontrado na natureza, apresenta 50 carbonos em sua cadeia, e sua biossíntese por M. luteus foi descrita por Netzer et al. (2010). Estudo recente com Kocuria palustris demonstrou a produção de sarcinaxantina (MENDESSILVA et al., 2021). Essas raras moléculas apresentam em suas estruturas múltiplas ligações duplas conjugadas $(\mathrm{C}=\mathrm{C})$ e contêm pelo menos um grupo $\mathrm{OH}$, as quais são responsáveis por suas propriedades antioxidantes e fotoprotetoras, que são atrativas para aplicações em composições cosméticas e farmacêuticas (NAGUIB, 2000; HEIDER et al., 2014). Os potenciais antioxidantes dos extratos brutos de $M$. luteus (FT-9.12 e FT-5.10) foram demonstrados pelos métodos de sequestro do radical DPPH, ABTS+, capacidade redutora dos íons ferro (FRAP) e inibição do sistema de oxidação do $\beta$-caroteno pelo ácido linoleico (Tabela 3). O extrato carotenoide de M. luteus FT9.12 na concentração de $400 \mu \mathrm{g} / \mathrm{mL}$ apresentou 78,65 $\pm 7,046 \%$ destacando-se na inibição da oxidação do $\beta$-caroteno pelo ácido linoleico. Com essa mesma concentração de extrato de Streptomyces Kumar et al. (2014) obtiveram 50\% de inibição utilizando esse método antioxidante. Assim, os dados encontrados aqui neste estudo demonstram uma alta eficiência antioxidante dos extratos de $M$. luteus, vislumbrando sua aplicação como antioxidante natural em diferentes setores industriais. Os resultados de absorbância dos extratos a $100 \mathrm{mgL}(290-320 \mathrm{~nm})$ foram submetidos a um tratamento matemático, e os valores do FPS foram determinados. O extrato do isolado M. luteus FT-9.12 apresentou 3,59 $( \pm 0,64)$ e o extrato do isolado FT5.10, 4,26 $( \pm 0,83)$. Esses valores de FPS encontrados aqui são considerados abaixo do valor mínimo de proteção solar, que segundo a Resolução Brasileira RDC n 30 de 01 de junho de 2012, deve ser 6,0 (Ministério da Saúde, 2012). Porém, ainda assim esses extratos carotenoides de $M$ luteus apresentam potencial para serem aplicados sinergicamente em loções fotoprotetoras, a fim de aumentar significativamente os FPS de filtros orgânicos. Assim como fez Suryawanshi et al. (2015), com a prodigiosina produzida pela bactéria Serratia marcescens, que isoladamente apresentava baixa fotoproteção, porém quando adicionada às loções aumentou os FPS de 15,24 e 40 , em $20 \%, 42 \%$ e $65 \%$, respectivamente.

\section{CONCLUSÕES}

De acordo com este estudo foi possível identificar dois novos isolados de $M$. luteus obtidos do solo da Caatinga, os quais se apresentam como uma boa fonte de produção de carotenoide raro, sarcinaxantina. Esses extratos carotenoides demonstraram potencial atividade antioxidante e fotoprotetora, sugerindo o uso destes como compostos bioativos em formulações fotoprotetoras.

\section{REFERÊNCIAS}

ALTSCHUL, S.F., et al. (1997). Gapped BLAST and PSIBLAST: a new generation of protein database search programs. Nucleic Acids Research. v. 25, p. 3389-3402. Disponível em: https://doi.org/10.1093/nar/25.17.3389.

APGAUA, D.M.G., et al. (2014). Beta-diversity in seasonally dry tropical forests (SDTF) in the Caatinga Biogeographic Domain, Brazil, and its implications for conservation. Biodiversity and Conservation, v. 23, p. 217-232. Disponível em: https://doi.org/10.1007/s10531-013-0599-9.

BLOIS, M.S. (1958) Antioxidant determination by the use of stable free radical. Nature, v. 181, p.1199-2000. Disponível em: https://doi.org/10.1038/1811199a0.

BONET et al. (2015) Carotenoids and their conversion products in the control of adipocyte function, adiposity and obesity. Archives of Biochemistry and Biophysics. v. 572, 112-125. Disponível em: https://10.1016/j.abb.2015.02.022.

BRASIL, MINISTÉRIO DA SAÚDE, Agência Nacional de Vigilância Sanitária. Resolução - RDC No 30 de $1^{\circ}$ de junho de 2012. Aprova o Regulamento Técnico Mercosul sobre Protetores Solares em Cosméticos e dá outras providências. Disponível em:<http://portal.anvisa.gov.br/wps/wcm/connect/e15afe804c58 f17fb8f0f8dc39d59d3e/Resolu\%C3\%A7\%C3\%A3o+RDC+N\% $\mathrm{C} 2 \% \mathrm{BA}+30,+\mathrm{de}+1 \% \mathrm{C} 2 \% \mathrm{BA}+\mathrm{de}+\mathrm{Junho}+\mathrm{de}+2012 . \mathrm{pdf}$ ?MOD $=$ AJPERES > Acesso em: 23 de set de 2015.

BRASIL. Ministério da saúde, Agência Nacional de Vigilância Sanitária. Detecção e identificação de bactérias de importância medica. Módulo V, p. 1-9. Brasília: Anvisa, 2004.

DUARTE, R.T.D., et al. (2012). Brazilian research on extremophiles in the context of astrobiology. International Journal of Astrobiology. v. 11, n.4, p.325-333. Disponível em: https://doi.org/10.1017/S1473550412000249.

GEVERS, D., et al. (2005). Re-evaluating prokaryotic species. Nature Reviews Microbiology, v.3, p.733-739. Disponível em: https://doi.org/10.1038/nrmicro1236.

HEIDER, S., et al. (2014a) Metabolic engineering fo rthe microbial production of carotenoids and related products with a focus on the rare C50 carotenoids. Applied Microbiology and 
Biotechnology. v. 98, p.4355-4368. Disponível em: https://doi.org/ 10.1007/s00253-014-5693-8.

HEIDER, S.; PETERS-WENDISCH, P.; WENDISCH,V. Carotenoid biosynthesis and overproduction in Corynebacterium glutamicum. BMC Microbiology v.12, p.1471-2180, 2012. Disponível em: https://doi.org/10.1186/1471-2180-12-198.

KABOUCHE, A., et al. (2007). Antioxidant abietane diterpenoids from Salvia barrelieri. Food Chemistry, v. 102, p. 1281-1287. Disponível em: https://doi.org/10.1016/j.foodchem.2006.07.021.

KAISER, P., et al. (2007) A small-scale method for quantitation of carotenoids in bacteria and yeasts. Journal of Microbiological Methods, v.70, n. 1, p. 142 -149. Disponível em: https://doi.org/10.1016/j.mimet.2007.04.004.

KIOKIAS S., PROESTOS C., VARZAKAS T. H. (2016) A Review of the Structure, Biosynthesis, Absorption of CarotenoidsAnalysis and Properties of their Common Natural Extracts. Current Research in Nutrition and Food Science Journal. v. 4(Carotenoids), p.2227. Disponível em: https://doi.org/10.12944/CRNFSJ.4.Special-Issue1.03.

KUMAR, P.P., RAJ, J.P., CHRISTHUDAS, I.V.S.N. (2014). $\alpha-$ Glucosidase inhibition and antioxidante properties of Streptomyces sp.: In vitro. Applied Biochemistry and Biotechnology. v.172, p. 1687-1698. Disponível em: https://doi.org/10.1007/s12010-013-0650-z.

MANIMALA M.R.A., MURUGESAN R. (2014). In vitro antioxidant and antimicrobial activity of carotenoid pigment extracted from Sporobolomyces sp. isolated from natural source. Journal of Applied and Natural Science. v.6, n.2, p.649 - 653. Disponível em: https://doi.org/10.31018/jans.v6i2.511.

MATA-GÓMEZ, L.C., et al. (2014). Biotechnological production of carotenoids by yeasts na orverview. Microbial cell factories, v.13, 12, 1-11. Disponível em: https://doi.org/10.1186/14752859-13-12

MELÉNDEZ-MARTÍNEZ, A.J., et al. (2007). Review: Analysis of carotenoids in Orange juice. Journal of food composition and Analysis, v. 20, p. 638-649. Disponível em: https://doi.org/ 10.1016/j.jfca.2007.04.006.

MENDES-SILVA, T.C.D, et al. (2021). Production of carotenoidsarcinaxanthin by Kocuria palustris isolated from Northeastern Brasil Caatinga Soil and their antioxidants and photoprotective activities. Electronic Journal of Biotechnology, no prelo.

MENDES-SILVA, T.C.D., et al. (2020). Biotechnological Potential of Carotenoids Produced by Extremophilic Microorganisms and Application Prospects for the Cosmetics Industry. Advances in Microbiology. v. 10, p.397-410. Disponível em: https://doi.org/10.4236/aim.2020.108029.

MENEZES, K.A.S., et al. (2015). Seedling development of nodulating and non-nodulating native legumes in soils from Brazilian Caatinga biome. Plant Science Today, v.2, n.2, p.5659. Disponível em: https://doi.org/10.14719/pst.2015.2.2.97.

MIKI W., et al. (1994). Okadaxanthin, a novel C50-narotenoid from a bacterium, Pseudomonas sp. KK10206c associated with marine sponge, Halichondria okadai. Experientia. Applied Microbiology and Biotechnology. v. 50, n.7, p.684-686. Disponível em: https://doi.org/10.1007/BF01952874.
MOHANA, D.C., THIPPESWAMY, S., ABHISHEK R.U. (2013) Antioxidant, antibacterial, and ultraviolet-protective properties of carotenoids isolated from Micrococcus spp. Radiation Protection and Environment. v.36, n.4, p. 168-174. Disponível em: https://doi.org/10.4103/0972-0464.142394.

NAGUIB, Y.M.A. (2000) Antioxidant Activities of Astaxanthin and Related Carotenoids. Journal of Agricultural and Food Chemistry. v.48, n.4, p.1150-1154. Disponível em: https://doi.org/10.1021/jf991106k.

NETZER, R., et al. (2010). Biosynthetic Pathway for -Cyclic Sarcinaxanthin in Micrococcus luteus: Heterologous Expression and Evidence for Diverse and Multiple Catalytic Functions of C50 Carotenoid Cyclases. Journal of Bacteriology. v. 192, p. 5688-5699. Disponível em: https://doi.org/10.1128/JB.0072410.

PELCZAR JR, J.M., CHAN, E.C.S., KRIEG, N.R. Microbiologia: conceitos e aplicações. 2ed. São Paulo: Pearson, 524p, 2012.

RE, R., et al. (1999). Antioxidant activity applying an improved ABTS radical cation decolorization assay. Free Radical Biology \& Medicine. v. 26, n. 9, p.1231-1237. Disponível em: https://doi.org/10.1016/S0891-5849(98)00315-3.

Sambrook, J., Russell, D.W. Molecular Cloning: A laboratory manual. Cold Spring Harbor Laboratory. 3rd ed, 2001.

SHINDO K.; MISAWA N. (2014). New and rare carotenoids isolated from marine bacteria and their antioxidant activities. Marine Drugs. v.12, n.3, p.1690-1698. Disponível em: https://doi.org/10.3390/md12031690.

SILVA, V.M.A.S., et al. (2015). Atividade Enzimática de Actinobactérias do Semiárido. Revista Brasileira de Geografia Física, v.08, p. 560-572. Disponível em: https://periodicos. ufpe.br/revistas/rbgfe/article/viewFile/233627/27217.

SOARES F.L, et al. (2012). Cellulolytic bacteria from soils in harsh environments. World Journal Microbiology Biotechnology, v 28, p. 2195-203. Disponível em: https://doi.org/10.1007/s11274012-1025-2.

SURYAWANSHI, R.K., et al. (2015) Towards na understanding of bacterial metabolites prodigiosin and violacein and their potential for use in comercial sunscreens. International Journal of Cosmetic Science. v. 37, p. 98-107. Disponível em: https://doi.org/10.1111/ics.12175.

UMADEVI, K., KRISHNAVENI, M. (2013). Antibacterial activity of pigment produced from Micrococcus luteus KF532949. International Journal of Chemical and Analytical Science, v.4, p. 149-152. Disponível em: https://doi.org/10.1016/ j.ijcas.2013.08.008.

VENTURA, M., et al. (2007). Genomics of Actinobacteria: tracing the evolutionary history of an ancient phylum. Microbiology and Molecular Biology Reviews, v.71, p. 495-548. Disponível em: https://doi.org/10.1128/MMBR.00005-07.

WEISBURG, W. G., et al (1991). 16S ribosomal DNA amplification for phylogenetic study. Journal of Bacteriology, v.173, p.697703. Disponível em: https://doi.org/10.1128/jb.173.2.697703.1991. 